\title{
TRANSFERÊNCIA DE TECNOLOGIA: OLHAR DA COMUNIDADE ACERCA DO NIÓBIO EM UMA ESCOLA ESTADUAL DO MUNICÍPIO DE LORENA, SÃO PAULO

\author{
Mariana Lindsay Santos Ferreira ${ }^{1}$ \\ Rosinei Batista Ribeiro² \\ William Brazil ${ }^{3}$
} \\ Bianca Siqueira Martins Domingos ${ }^{4}$
}

Resumo: Esta pesquisa visa apresentar e discutir criticamente os resultados de uma pesquisa sobre o conhecimento de alunos e professores de uma escola estadual sobre o nióbio como forma de endossar a demanda pela difusão e popularização do metal no Brasil. A aplicação do questionário foi parte do projeto que tem como objetivo desenvolver um documentário intitulado "Tecnologia Mineral Brasileira: Recontando a História do Nióbio", que contará com entrevistas com docentes, pesquisadores e técnicos, com a posterior difusão por meio das redes sociais, como o Youtube e Facebook. A metodologia abrangeu a aplicação de questionário semiestruturado com amostragem probabilística estratificada.

Palavras-chave: Nióbio; Divulgação Científica; Difusão e Popularização; Estudo de Caso.

\footnotetext{
${ }^{1}$ Ensino Médio/Escola Estadual Professor Luiz de Castro Pinto, Brasil. E-mail: marisantos1557@gmail.com.

2 Instituto Superior de Pesquisa e Iniciação Científica/Centro Universitário Teresa D’Ávila, Brasil. E-mail: rosinei.ribeiro@pq.cnpq.br.

3 Instituto Superior de Pesquisa e Iniciação Científica/ Centro Universitário Teresa D’Ávila, Brasil. E-mail: william_brazil@msn.com.

4 Instituto Superior de Pesquisa e Iniciação Científica/ Centro Universitário Teresa D’Ávila, Brasil. E-mail: biancasiqueira.m@gmail.com.
} 